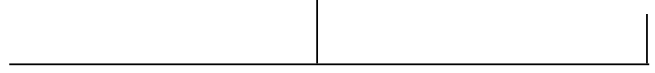

Rev. Latinoam. Psicopat. Fund., São Paulo, v. 14, n. 2, p. 367-382, junho 2011

\title{
Henry Ey, Jackson e as ideias obsessivas*
}

German E. Berrios

\begin{abstract}
$O$ artigo destaca a importante contribuição do professor de psiquiatria Henry Ey aos estudos sobre John Hughlings Jackson. Analisa historicamente uma interface pouco conhecida de Jackson com a psiquiatria: o diálogo sobre as "ideias obsessivas" que figura nas páginas da revista Brain, entre 1894 e 1895. Discute as razões históricas que podem explicar a não influência de Jackson na psiquiatria britânica, em contraste com a ampla difusão de suas posições no campo da neurologia.
\end{abstract}

Palavras-chave: Ideias obsessivas, John Hughlings Jackson, Henry Ey, psicopatologia - história

* Publicado originalmente como: Henry Ey, Jackson et les idées obsédantes. L'Évolution Psychiatrique, Toulouse, tomo 42, fasc. III/2, n. especial, 1977 (tradução do inglês ao francês de Thierry Eydoux). Tradução para o português de Martha Gambini e revisão técnica de Ana Maria G. R. Oda.

A tradução de obsédant/obsessionnel foi padronizada como 'obsessivo’ (N. da RT.). 
A contribuição de altíssimo nível do professor Ey aos estudos jacksonianos não recebeu apreciação à altura de seu valor na Grã-Bretanha. As razões dessa imperdoável indiferença são múltiplas. Vou me adiantar, afirmando que elas são de três ordens: em primeiro lugar, a atitude muito curiosa (comum nesse país até certa data) em relação à história; a seguir, um estilo de pensamento peculiar à psiquiatria britânica que, aliás, apresso-me a dizer, foi magistralmente analisado pelo próprio professor Henry Ey em seu Estudo número 3 (Ey, 1952); e, finalmente, uma consideração prática que não deixa de ter importância: o fato de a obra do professor Ey (com exceção de alguns capítulos ou de alguns curtos artigos introdutórios) não ter sido traduzida para o inglês. Isso para dizer que o psiquiatra inglês médio não tinha como travar conhecimento com os escritos do Mestre. Mas os cínicos dirão: por que toda essa história nesse caso particular? No final das contas, muitos grandes psiquiatras do continente já foram vítimas de tal ostracismo. E eles não deixarão de acrescentar que, aqui, o obstáculo não é a barreira da ignorância, mas a diferença de mentalidade entre os continentais e os ingleses, diferença já notada por Pierre Duhem, em 1914, em seu livro A teoria física (Duhen, 1954). Aos cínicos, responderemos simplesmente que nenhum desses grandes psiquiatras continentais negligenciados forneceu-nos um trabalho de exegese sobre as ideias de um médico britânico comparável ao de Henry Ey. Ainda mais se tratando de Hughlings Jackson, o mais eminente neurólogo britânico.

E isso não é nada desprezível. Esse homem de Yorshire não era especialmente reputado pela limpidez de suas apresentações ou por seu gosto pela teoria. Suas volumosas produções são frag- 
mentárias, repetitivas e redundantes. Suas contribuições conceituais, certamente muito importantes, encontram-se dispersas em comentários de casos, artigos, notas e outros. E, quando ele tenta ser abertamente teórico, sua adesão ingênua a ideias filosóficas populares, e até mesmo a lugares comuns (a doutrina da concomitância, por exemplo), esconde a profundidade de seu pensamento. Mas isso nunca desestimulou o professor Ey. Com uma escrupulosa aplicação, ele conseguiu extrair e reconstituir o pensamento de Jackson a partir dos textos. Esse trabalho teve como resultado trazer aos psiquiatras, neurologistas e historiadores ideias e um conhecimento sobre o cientista britânico muito mais considerável do que tudo que havia sido escrito deste lado da Mancha. Além disso, a exegese do professor Ey nos ensina que a trama conceitual utilizada por Jackson para dar uma unidade a suas concepções sobre a epilepsia e a afasia pode ser utilizada em psiquiatra. Dessa forma, o professor francês não somente reuniu neurologia e psiquiatria, mas também se esforçou para preencher o hiato criado, há trezentos anos, pelo inimigo comum: o "cartesianismo".

\section{Posição do problema}

Ao revelar a pertinência do jacksonismo para a psiquiatria, o professor Ey levanta um enigma que escapou, até onde eu saiba, aos historiadores da psiquiatria britânica. Ei-lo: admitindo-se que o professor Ey tenha razão em sua interpretação de Jackson, devemos perguntar: por que este último não influenciou a psiquiatria britânica de modo durável? Em outros termos: por que a posição dominante de Jackson em neurologia não foi acompanhada por uma posição equivalente na psiquiatria?

Desconfio que esta questão, aparentemente simples, tenha uma resposta um pouco mais complicada. Essa complexidade deve-se muito menos a uma documentação rara ou obscura (pois na verdade dispomos de um material extenso e bem escrito), e bem mais ao que, nesse caso particular, seriam as fronteiras do que Michel Foucault (1969) chamou de "arqueologia", em feliz expressão. Com certeza é possível, de forma geral, fornecer uma resposta. Talvez a psiquiatria britânica tenha simplesmente sido tão habitada pelo espectro da "posição mecanicista" que os princípios de Jackson não conseguiram penetrá-la. Mas essa resposta é excessivamente vaga. Seria necessário aprofundar tal explicação pois, no final das contas, seria possível retomar as perspectivas de Jackson sobre a afasia e a epilepsia em termos de "conceito de centros de imagens" - como fez o professor Ey (1952), em termos gerais, em seu Estudo número 3 - o que o faria entrar nas fileiras dos "mecanicistas". 
O que mais então poderia ter impedido que as ideias de Jackson penetrassem a psiquiatria? Se os conhecimentos sobre Jackson são em geral bastante exíguos, aqueles que tratam especificamente das relações de Jackson com a psiquiatria o são ainda mais. A leitura dos primeiros trabalhos (com promissores títulos) não parece ser particularmente esclarecedora. Na realidade, para mim foi difícil acrescentar o menor texto à lista reunida pelo próprio professor Ey em uma nota de seu Estudo número 7 (1952). Excelentes revisões recentes da literatura (López-Pinero, 1973; Engelhart, 1975) não fornecem referências suplementares à lista e, portanto, podemos concluir tratar-se de um campo de pesquisa pura $\mathrm{e}$ simplesmente negligenciado.

Os artigos clássicos não ajudam muito mais. Savage (1917) é excessivamente desarticulado e superficial. Levin (1933) foca demais o aspecto neurológico e contém um número excessivo de lugares-comuns. Stengel (1963) insiste muito sobre a relação Jackson-Freud, mas em lugar nenhum menciona o problema essencial: por que essa falta de influência sobre a psiquiatria britânica? Delay (1957), num ensaio histórico, busca esclarecer, a meu ver sem sucesso, as relações de Jackson com o editor da Revue Philosophique. Rouart (1950), num artigo bastante interessante, conseguiu colocar em relevo as similaridades (e as diferenças!) entre Jackson e Janet.

Mas ainda há mais. Os trabalhos de síntese sobre a noção jacksoniana de consciência (Riese, 1954), sobre a doutrina da concomitância (Angel, 1961; Engelhart, 1975; Levin, 1960; Podolsky, 1947; Prince, 1891), sobre o mentismo (Levin, 1933) etc., embora úteis como noções de base, nada nos informam quanto ao enigma que nos preocupa. Assim, onde encontrar a solução? De forma geral, vejo duas saídas possíveis para essa história: ou conseguimos mostrar que, em nível simultaneamente conceitual, profissional e pessoal, houve profundas diferenças entre Jackson e os alienistas seus contemporâneos que controlavam o universo da psiquiatria britânica oficial após 1860; ou, então, se realmente quisermos ser bizantinos, podemos dizer que, compartilhando o conjunto da tradição intelectual pós-darwiniana, Jackson e os alienistas de seu tempo concordavam num nível tão profundo que estes últimos não teriam necessidade de reconhecer publicamente a influência daquele. No fundo, a escolha entre essas duas interpretações dependerá mais da maneira pela qual estaremos dispostos a utilizar o conjunto completo e detalhado das ideias de Jackson e menos de saber se encontramos traços de sua influência em dado autor.

Inclino-me mais para a primeira hipótese. Em primeiro lugar, há boas razões para se pensar que os psiquiatras britânicos (de hoje e de então) consideraram as ideias jacksonianas abstratas demais para a clínica cotidiana, e que não seria possível extrair qualquer conclusão prática ou terapêutica de um fato teórico, diga- 
mos, por exemplo, o de um paciente sofrendo de uma "dissolução" de seu sistema nervoso. Mas os historiadores da psiquiatria não podem adotar a mesma atitude, pois seus problemas começam precisamente onde terminam os do clínico. Eles devem explicar as razões pelas quais os clínicos consideraram as ideias de Jackson excessivamente abstratas, e porque foram incapazes de extrair delas "conclusões terapêuticas".

Os historiadores perceberam rapidamente não se tratar aqui de uma questão de lógica ou heurística, mas de uma questão de moda e de conveniência dos cânones científicos em dada sociedade. Pois ainda que noções como "gramática do eu", superego", "universais da linguagem" etc. sejam quase tão abstratas quanto a de "dissolução", elas não deixam de desempenhar um papel essencial em psiquiatria nas habituais "terapias" da moda.

Como o historiador vai se arranjar em meio a toda essa história? Pressuponho que seja uma questão de escolha pessoal. E se for assim, antes de produzir uma teoria capaz de explicar nosso enigma, cabe realizar pesquisas limitadas para reforçar nossos argumentos. Temos que saber mais sobre os contatos reais de Jackson com seus pacientes psiquiátricos, sobre suas ideias, seus problemas e sobre os contatos que manteve com os próprios alienistas. Ainda que isso seja exato, não basta saber, como relata Savage, que Jackson

... não queria ter nada a ver com os doentes mentais caso pudesse evitá-los... pois estes o deixavam perplexo e o transtornavam. Em certos momentos ele parecia ter um real medo físico dos doentes e perdia o calor humano que demonstrava junto aos epilépticos. Considerava muitos desses loucos inúteis, antes de incômodos. (Savage, 1917)

Saber isto não basta, pois no final das contas (e apesar de sua antipatia com relação aos doentes mentais, que traduzia provavelmente um desinteresse quanto à observação real do comportamento), as ideias de Jackson poderiam servir para fornecer explicações sobre o comportamento dos doentes, independentemente dos sentimentos pessoais a seu respeito.

É nesse sentido que os fatos históricos pontuais podem se mostrar úteis. Eles podem trazer o aprofundamento da visão num campo limitado, pois ganham em profundidade o que perdem em extensão. Felizmente, a publicação de um bom número de fatos históricos referentes aos contatos de Jackson com a psiquiatria fornece material suficiente para que alguém com o poder de síntese do professor Ey possa dele extrair conclusões.

Assim, nas páginas seguintes, e em homenagem ao professor Ey por seu septuagésimo aniversário, irei expor (na medida do possível) uma curta apresentação histórica sobre um contato desconhecido de Jackson com a psiquiatria, ou 
seja, o diálogo sobre as "ideias obsessivas" que figura nas páginas de Brain (1894-1895) entre os diversos protagonistas: Hâch Tuke (1894), Jackson (1895), Mercier (1895), Savage (1895) e Bramwell (1895).

\section{As "ideias obsessivas" e seu contexto histórico}

A história da clínica da obsessão e dos fenômenos ligados a ela não foi abordada corretamente pelos historiadores da psiquiatria. As obras clássicas, como as de Kraepelin (1962), Zilboorg (1941), Ackerknecht (1968), mal aludem a ela. É praticamente impossível encontrar uma análise adequada, e as revisões gerais da literatura são fragmentárias e incompletas. Ainda e sempre, os raros esclarecimentos nos são fornecidos pelo importante, mas infelizmente excessivamente curto, trecho do professor Ey em seu Estudo número 3 (1952). Aí ele parece sustentar que o nascimento do conceito de sintoma obsessivo deveria ser considerado consequência do processo mais amplo de desintegração da psicopatologia unitária do século XIX. A semiologia atomística que se seguiu (consequência do novo entusiasmo pelos fenômenos sensoriais elementares) isolou a obsessão, separou-a do resto da personalidade do obsessivo, conseguindo reduzi-la, como ele formula de modo soberbo, a um "corpo estranho, como um cisco sobre a conjuntivite".

$\mathrm{Na}$ verdade, o que na época preocupava o professor Ey, e o que preocupou muita gente desde então, era o problema da escolha das unidades que pudessem servir para a análise do comportamento. Parece claro que em certo momento do século XIX ocorreu uma mudança na maneira de se conceituar o comportamento. Essa mudança, que pode ser encontrada no que Henry Ey chamou de "a pulverização atômica da semiologia", deveria entretanto ser compreendida com a ajuda de um modelo mais detalhado do que aquele apresentado pelo Mestre francês em seu Estudo número 3. Assim, além do fato geral de que havia na ciência do século XIX uma tendência para a explicação mecanicista, é preciso identificar as variáveis significativas em jogo. Uma dentre elas foi, certamente, a oposição entre a psicologia das faculdades e o associacionismo durante o século XIX. Como não há espaço neste curto artigo para simplesmente tentar resumir os principais aspectos desse debate (do qual me ocupei em outra parte) (Berrios, 1975) limitar-me-ei a fazer três declarações abruptas: em primeiro lugar, é muito difícil compreender a história da noção de "obsessão", sem fazer referência à história da psicologia das faculdades; em segundo lugar, o que pode ser chamado de "erro mecanicista" não possui um poder explicativo suficiente para dar conta da pulverização da superfície comportamental em síndromes clínicas realizada nessa 
época; em terceiro lugar, não existe qualquer razão a priori (fora aquela extraída de modelos estéticos, éticos ou teológicos do homem) para designar como sendo boa para esse período histórico (ou para qualquer outro) uma teoria não mecanicista, de preferência a uma teoria mecanicista. Um corolário dessa última afirmação é que os elementos que determinam a escolha de uma teoria nada têm a ver com "a ciência" ou com o "progresso"; essa escolha depende apenas de fatores "extracientíficos". Essas regras constituem o que o jargão moderno nomeia de "a construção social da realidade" ou a "episteme".

Mas voltemos ao nosso tema. Descrições do fenômeno obsessivo (sob diversos nomes ou totalmente sem rótulo!) aparecem muito cedo nos documentos históricos ocidentais. Em Anatomia da melancolia de Burton (1833) ou na Antologia de Hunter e Macalpine (1963) encontramos referências ao "comportamento escrupuloso" associado na maior parte do tempo a uma excessiva preocupação religiosa. O século XIX concluiu a "medicalização" da loucura e outros "comportamentos bizarros"; as causas desse movimento preocuparam importantes cientistas (entre os quais o próprio professor Ey). Os historiadores franceses do fim do século XIX (Ladame, 1890; Ball, 1892; Ritti, 1828, entre outros) e os últimos autores alemães (Warda 1905; Schneider, 1918 etc.) fizeram frequentes alusões à charmosa descrição feita por Esquirol da srta. F. Mas ninguém cita o que Esquirol (1838) diz três páginas adiante:

Os doentes sofrendo dessa variedade de loucura têm realmente um delírio parcial; eles realizam ações, dizem coisas estranhas, singulares, absurdas, que eles reconhecem como tais e que eles reprovam. Entre esses doentes, alguns são turbulentos, insociáveis, cometem ações ridículas, censuráveis, contrárias a seus afetos anteriores e a seus verdadeiros interesses.

Aqui, Esquirol chega a identificar de modo mais ou menos bem-sucedido, os dois critérios fundamentais que os teóricos da obsessão esforçaram-se por definir e que foram muitas vezes atribuídos erroneamente a Westphal ou, pior ainda, a Schneider. A história desses fenômenos culmina por volta dos anos 1890 , no momento em que nosso debate se instaura (para uma apresentação detalhada, ver meus outros artigos [Berrios, 1985, 1989]). De um lado havia o esforço de se isolar as obsessões (Zwangsvortellungen, imperative notion", mental besetments, Anancasms etc.) (Donath, 1897) como unidades psicopatológicas suscetíveis de serem analisadas; esse procedimento analítico provinha da corrente "atomística" que o professor Ey descreveu em outro contexto. De outro lado, buscava-se distinguir uma série de síndromes onde as obsessões eram um elemento importante, mas que deveriam ser consideradas doenças por inteiro (Folie du doute, Délire du toucher, Grubelsucht, Pazzia del dubbio, Introspective Insanity, Formes psychasthéniques). Um inventário superficial da psicopatologia 
dessas entidades mostra, evidentemente, que sua gramática profunda, se assim podemos dizer, foi reinterpretada em função das teorias em voga: fadiga cerebral, teoria da degenerescência, psicologia das faculdades. A velha dicotomia possessão-obsessão, de conotação teológica, reaparece uma vez mais na questão de se saber se as obsessões podem evoluir na direção dos delírios. Um trabalho análogo foi realizado sobre outras fronteiras: fenômeno alucinatório, depressão, síndrome orgânica, histeria etc.

Da mesma forma, o problema da gênese das obsessões começa a ser articulado de forma bem-sucedida. É digno de nota que no período (definido pelos historiadores clássicos da psicologia) durante o qual o associacionismo prevalecia, com Wundt e outros, a questão de saber se a origem das obsessões era essencialmente "intelectual", "emocional", ou "volitiva" (e cada uma dessas teorias tinha muitos partidários) foi fundamentalmente colocada em termos pertencentes à psicologia das faculdades. E é também notável que durante o período no qual a vontade enquanto faculdade desempenha um papel muito importante como unidade de análise (tanto no âmbito da psicologia, quanto no da psicopatologia, da educação, da política social etc.) (Berrios, 1974; Billod, 1847), essa unidade não chega a ocupar o primeiro lugar quando se trata de explicar as obsessões. Foi sobretudo a teoria intelectualista que conseguiu reunir os homens mais influentes da época (Griesenger, Westphal, Magnan etc.). O fato de a linguagem da psicologia das faculdades ser ainda dominante nessa época aparece claramente no belo artigo de Brierre de Boismont (1853) onde a noção de "unidade do Eu", é dirigida contra a psicologia das faculdades. No fim desse período, pode-se encontrar ainda outro artigo (Arnaud, 1902), que embora em nível mais experimental, desenvolve seus argumentos de modo bastante convincente no quadro da mesma trama conceitual.

\section{Jackson e as ideias obsessivas}

Onde se situa, nesse conjunto, nossa discussão sobre "as ideias obsessivas"? Tudo começou com o artigo de Hâch Tuke publicado em Brain, em 1894. Originalmente, tratava-se de uma conferência proferida diante da Neurological Society em $1^{\circ}$ de março do mesmo ano. Não era um trabalho de erudição, e levando-se em conta a data da publicação, esse artigo não constitui uma contribuição original para o problema. Limita-se a um resumo de algumas ideias que na época eram correntes sobre o assunto e à descrição de alguns casos (ao mesmo tempo em que escamoteava algumas colocações interessantes de um "jovem” cha- 
mado Pierre Janet). O primeiro parágrafo contém uma citação dos Neurological Fragments de Jackson, e se encerra com a seguinte confissão, de uma candura desconcertante: "aqueles que se familiarizaram com os autores alemães e franceses acharão que a descrição feita por eles do fenômeno mental é de longe muito mais clara que a nossa". Aubrey Lewis (1957) formula uma asserção semelhante mais de sessenta anos depois.

No entanto, não é nem um pouco evidente que Tuke se interessasse há muito tempo pelo assunto. Na terceira edição de seu manual (em colaboração com Buckwill, em 1874) ele não menciona fenômenos obsessivos. Assim, é completamente possível que seu artigo seja um condensado do material que ele acumulara sobre o mesmo assunto para seu Dicionário (Tuke, 1892). A excelente revisão da literatura sobre a Zwangszustande por Warda (1905) menciona e resume, 11 anos mais tarde, o artigo de Tuke.

Apesar da amplidão dos estudos continentais sobre os fenômenos obsessivos, Tuke "lamenta que tenham sido excessivamente perdidos de vista os traços característicos da doença de que sofrem tais sujeitos". Ele reúne então todos esses fenômenos e (como era de costume então) coloca-os no grupo das síndromes fóbicas (a esse respeito é muito interessante notar que pelo menos um autor tenha encontrado uma maneira de escrever uma história das fobias sem mencionar a história dos distúrbios obsessivos! - Errera, 1962). Depois, Tuke prossegue passando em revista o que considera serem os traços essenciais desse estado: $o$ automatismo, o caráter não delirante, o aspecto invasivo, o fato de que ele dá lugar a atos impulsivos, o alívio que tais atos proporcionam em termos de descarga energética. O interesse do artigo refere-se à interpretação de Tuke sobre as ideias obsessivas a partir da velha hipótese de Laycock sobre a "função reflexa ou automática do cérebro". Utilizando o princípio de "associação", Tuke explica a natureza obsessiva da ideia que, dependendo do caso, pode "se inscrever profundamente, como se estivesse localizada no neurônio vesicular". E acrescenta: "Laycock admitiu o controle exercido pelo córtex cerebral sobre as impressões sensoriais, mas não conseguiu ir além das doutrinas correntes relativas ao controle de uma parte do córtex sobre outra". Para explicar o fenômeno obsessivo, Tuke refere-se a uma ideia que Legrain (entre outros) havia levantado sobre a possibilidade de um centro subcortical que escaparia repentina e isoladamente do controle, funcionando de maneira autônoma. É nesse momento que ele faz referência a Jackson: "Penso que em nenhum de seus escritos o dr. Jackson falou das ideias obsessivas a não ser como ideias delirantes". Aqui, Tuke parece bastante surpreso pelo fato de que, estando tão perto das ideias obsessivas (Jackson havia construído uma teoria para dar conta dos delírios), o cientista britânico não tenha aplicado a elas as suas teorias. 


\section{Depois, ele continua:}

Quais são as condições cerebrais que acompanham as ideias obsessivas? O mais automático não está mais sob o controle dos níveis cerebrais (ou das camadas cerebrais) voluntárias ou menos automáticas. Em termos jacksonianos, foi produzida uma reversão da evolução, ou seja, uma redução do menos organizado ao mais organizado dos centros cerebrais mais elevados.

Jackson respondeu em 1895. Tuke certamente leu esse artigo (sem contar os de Savage, Mercier e Milne Branwell, publicados no mesmo número de Brain), mas morreu antes de conseguir responder a ele. Jackson admitia que "embora tenha visto vários casos caracterizados pelo que o dr. Tuke chama de 'ideias obsessivas', infelizmente não lhes concedi muita atenção no plano científico e não lhes conferi um lugar tão importante quanto o que o dr. Tuke lhes atribuiu com talento". Ele também reconhece ter dito que a origem dos delírios devia-se "à fixação de fantasias oníricas provocadas pelo acontecimento brusco de uma modificação patológica no cérebro ou por uma mudança brutal no sono". Mas logo se apressa em temperar o entusiasmo de Tuke quanto a uma extensão dessa hipótese às ideias obsessivas: "eu não aplicaria sem reservas essa hipótese aos casos descritos pelo dr. Tuke". E acrescenta:

No entanto, talvez algumas ideias incômodas, até aqui fugazes, se fixem, tornando-se ideias obsessivas após uma modificação mórbida do cérebro que ocorra durante o sono. De fato, acredito que o dr. Tuke queira dizer que um estado mental normal, aquele que pelo menos é comumente partilhado por pessoas consideradas em boa saúde, fixa-se mais ou menos quando o estado de saúde se altera ou quando uma modificação mórbida quase insignificante acontece no próprio cérebro.

Até aqui tudo vai bem. Jackson optava por uma teoria psicológica estabelecendo uma continuidade entre a pessoa escrupulosa e a pessoa obsessiva; e, no plano etiológico, afirmava vigorosamente que as obsessões não eram, no final das contas, senão formas menores de delírios. Mas isso só se sustentava em função de uma teoria "traumática", onde algo acontece bruscamente para fixar a ideia. Uma vez mais, seu robusto bom senso médico prevalece: "devemos com certeza explicar a existência desses estados quase parasitas nos casos em que as faculdades mentais não foram praticamente atingidas".

Jackson tinha clareza de que não é possível responder tal questão, a menos (e esse a menos é importante) que se apele para um argumento estrangeiro ao debate: o da "predisposição hereditária".

A continuação de seu artigo resume suas ideias bem conhecidas sobre os sintomas positivos e negativos na doença mental (ideias atribuídas a Monro!) e o 
princípio da liberação do centro inferior após a destruição do centro superior (princípio atribuído a Anstie!).

O artigo de Jackson não passa totalmente despercebido, mas não é mencionado nem na monografia de Warda, nem na de Schneider. Savage, em seu artigo de 1917 sobre Jackson, ressalta que no artigo de Brain sobre as ideias obsessivas "havia algo de muito original", ou seja, "a fixação da ideia dando lugar às ideias obsessivas ou às ideias fixas”. Mas então Savage nota uma contradição na apresentação de Jackson:

A respeito do desenvolvimento das ideias fixas ou das ideias obsessivas, Jackson diz que pode não haver sintomas positivos incômodos quando uma doença do nível mais alto progride lentamente (o controle só desaparece lentamente). Quando a evolução é rápida, a atividade mental (embora ainda possível) diminui muito depressa (o controle desaparece rapidamente). Num certo sentido, há algo contraditório em se afirmar que as ideias obsessivas podem se desenvolver tão lentamente ao mesmo tempo em que podem se tornar parasitas devido à fixação durante o sono.

Embora neurologizante em suas explicações, nesse artigo Jackson alinhou-se ao grupo dos alienistas que preconizavam uma explicação "emocional" ou "traumática" das ideias obsessivas. O que de certa maneira os alienistas afirmavam é que o conteúdo intelectual da obsessão devia-se ao acaso, e que o que contava para o desenvolvimento de sintoma era uma modificação súbita do conjunto das estruturas psicológicas, modificação durante a qual qualquer ideia poderia ser fixada. Assim, a natureza da alteração estrutural pode ser concebida de modo diferente: em termos puramente psicológicos (paixão ou emoção); em termos neurológicos (centros cerebrais); em termos de energia psíquica ligada a qualquer ideia vizinha (Freud, 1895); ou, finalmente, em termos de um estado de grande excitação tornando o sistema vulnerável diante de dada situação de aprendizagem (Pavlov, 1934).

Portanto, é estranho que um livro recente sobre os "Estados obsessivos" (Beech, 1974) não mencione a grande tradição dos "partidários da emoção", tradição na qual há cem anos é discutida uma teoria que ela teve mesmo a pretensão de ter criado. Nesse contexto, não deveriam ser esquecidos os nomes de Morel, Legrand du Saulle, Janet, Wernicke, Féré, Pitres, Régis etc.

Os três outros artigos publicados ao mesmo tempo não têm muita relação com o tema. Savage encontrou uma maneira de compor uma miscelânea com as principais ideias de Tuke. Mercier, com sua costumeira vaidade, declara que Tuke nada fizera além de repetir aquilo que ele, Mercier, já dissera há muito tempo. Bramwell aproveitou a ocasião para exaltar os méritos do hipnotismo e esboça uma monografia tão longa quanto incompleta sobre a história do fenômeno obsessivo. 
A maioria de suas fontes são retiradas de artigos da Revue de l'hypnotisme, e particularmente do de Landame (artigo quase idêntico à sua monografia de 1890 nos Annales Médico-Psychologiques). De fato, muitos anos mais tarde, na terceira edição de seu livro sobre o hipnotismo, Bramwell retomou uma vez mais, quase palavra por palavra, o essencial de seu artigo.

A ideia de que a história possa ser considerada pura e simplesmente fonte de erros sempre me assombrou. Com certeza, uma boa resenha diacrônica encerra fascinação e coerência profundas que bastariam a si próprias. Mas não se pode afastar a ideia de que a história seja o cadinho conceitual onde se desenrola o drama das ideias. No final das contas, essa espécie de compreensão genética do espetáculo oferecido pela abordagem diacrônica somente enriquece a psiquiatria clínica. É precisamente esse o uso que o professor Ey fez da história, e devemos agradecê-lo por essa magistral lição. Talvez em nossos dias a psiquiatria estivesse menos embaraçada por conceitos sofisticados se, de vez em quando, ela desse uma olhada para trás e compreendesse o que estava em jogo em certas batalhas conceituais que os psiquiatras de antigamente sentiram-se capazes de travar.

\section{Referências*}

ACKerknecht, E.H. A Short Hystory of Psychiatry. New York: Hafner, 1968.

Angel, R.W. Jackson, Freud and Sherrington on the relationship of brain and mind. Amer. J. Psychiat., n. 118, p. 193, 1961.

Arnaud, F.L. Sur la théorie de l'obsession. Arch. De Neurol., n. 13, p. 257, 1902.

Ball, B. Doubting insanity. In: Tuke, H. (ed.). Dictionary of Psychological Med. Londres: Churchill, 1892. v. I.

Beech, H.R.; Périgault, J. Toward a theory of obsessional disorder. In: BeEch, H.R. (ed.). Obsessional States. Methuen, 1974.

Berrios, G.E. Will and Insanity in $19^{\text {th }}$ Century. Psychiatry Paper delivered at Departmental Psychiatric Meeting, Universidade de Leeds, 1974. . Faculty Psychology and Insanity in $19^{\text {th }}$ Century. British Psychiatry, Paper lido no Wakefield Meeting do Royal College of Psychiatrists (não publicado), 1975. . Obsessional disorders during the nineteenth century: terminological and

* As referências Ellenberg (1970), Hitzig (1900) e Mayer (1901) não se encontram no corpo do artigo original. (N. da RT.) 
classificatory issues. In: The anatomy of madness. Essays in the History of Psichiatry. Londres e New York: Tavistock Publications, 1985. v. I.

. Obsessive-compulsive disorder: its conceptual history in France during the 19th century. Comprehensive Psychiatry, v. 30, n. 4, p. 283-295, Jul/Aug. 1989.

Billod, E. Maladies de la volonté. Am. Med. Psych., n. 10, p. 15, 170, 317, 1847.

Bramwell, J.M. On imperative ideas. Brain, n. 18, p. 331, 1895.

. Hypnotism, its History Practice and Theory. Londres: William Rider, 1921.

Brierre de Boismont. De l'état des facultes dans les délires partiels ou monomanies. Am. Med. Psychol., n. 5, p. 567, 1853.

Burton, R. The Anatomy of Melancholy. Londres: Chatto and Windus, 1883.

Delay, J. Jackonism and the works of Ribot. Arch. Neurol. et Psychiat., n. 78, p. 505, 1957.

Donath, J. Zur Kenntniss des Anancasmus (psychische Zwangszustande). Arc. Fur Psychiat., n. 29, p. 211, 1897.

Dunen, P. The Aim and Structure of Physical Theory. Princeton, 1954.

ElLenBerg, H.F. The Discovery of the Unconscious. Londres: Allen Lane, 1970.

Engelhart, H.T. J. H. Jackson and the the mind body problem. Bull. Hist. Med., n. 49, p. $137,1975$.

Errera, P. Some historical aspects of the concept of phobia. Psychiatric Quarterly, n. 36, p. 325, 1962.

Esquirol, E. Des maladies mentales. Paris: J-B Ballière, 1838. V. II.

Ey, H. Études Psychiatriques - tome I. Paris: Desclée de Brouwer, 1952.

Foucault, M. L'archéologie du savoir. Paris: Gallimard, 1969.

Freud, S. Obsessions et phobies. Revue neurologique, n. 3, p. 33, 1895.

Hitzig, E. Hughlings Jackson and the cortical motor centres in the light of physiological research. Brain, n. 23, p. 545, 1900.

Hunter, R.; Macalpine, I. Three Hundred Years of Psychiatry. Oxford University Press, 1963.

JACKSON, H. On imperative ideas. Brain, n. 18, p. 318, 1895.

Kraepelin, E. One Hundred Years of Psychiatry. Londres: Peter Owen, 1962.

Ladame. La folie du doute et le délire du toucher. Ann. Med. Psychol., n. 12, p. 368386, 1890.

Levin, M. Hughlings Jackson's views on Mentation. Arch. Neurol. Psychiat., n. 30, p. 848, 1933. 
. The mind-brain problem and Hughlings Jackson's doctrine of concomitance. Amer. J. Psychat., n. 116, p. 718, 1960.

Lewis, A. Obsessional illness. Acta Neuropsychiatrica Avg., n. 3, p. 323, 1957.

LóPEZ-PIÑERo, J.M. John Hughlings Jackson. Madrid: Editorial Moneda y Credito, 1973.

MAYER, E.E. Evolutional and involutional types of mental and nervous disease. J.A.M.A., n. 36, p. 441, 1901.

Mercier, C. On imperative ideas. Brain, n. 18, p. 328, 1895.

PavLov, I.P. An attempt at a physiological interpretation of obsessional neurosis and paranoia. J. Mental Sci., n. 80, p. 187, 1934.

Podolsky, E. Hughlings Jackson and thinking machine. Med. Rec., n. 160, p. 676, 1947.

Prince, M. Hughlings Jackson on the connection between the mind and the brain. Brain, n. 14, p. 250, 1891.

RIESE, W. Hughlings Jackson's doctrine of consciouness. J. Nerv. Ment. Dis., n. 120, p. 331, 1954.

Ritri, M. Folie de doute. Artigo no Dictionnaire encyclopédique des Sciences médicales, 1828.

RouART, J. Janet and Jackson. Évolution psychiatrique, p. 485, 1950.

SAVAGE, C.H. On imperative ideas. Brain, n. 18, p. 322, 1895.

SAvage, C. Dr. Hughlings Jackson on mental disorder. J. Mental Sci., n. 63, p. 315, 1917.

SchNeIDER, K. Die Lehre vom Zwangsdenken in den letzten 12 Jahren. Zeitschr. F. $d$. Ges. Neur. V. Psych., n. 16, p. 113, 193, 1918 (Referatentell).

Stengel, E. Hughlings Jackson's influence in psychiatry. Brit. J. Psichiat., n. 109, p. 348, 1963.

Tuke, H.D. Imperative ideas. Dictionary of Psychological Medicine. Churchill, 1892. v. I.

TUKE, H. Imperative ideas. Brain, n. 17, p. 179, 1894.

Warda, W. Zur Geschhichte und Kritik der Sogenannten Zwangszustande. Arch. Fur Psychat., n. 39, p. 239-285, 535-585, 1905.

Westphal. Zwangsvorstellungen. Arch. Fur Psychiat., n. 8, p. 734, 1877.

ZiLboorg, G. A History of Medical Psychology. Nova York: W.W. Norton \& Co. 1941. 
(Henri Ey, Jackson and obsessive ideas)

This article highlights the important contribution of the French psychiatrist Henry Ey, to studies on John Hughlings Jackson. It historically analyzes a little-known text that presents an interface between Jackson and psychiatry, namely: Dialogue on "Obsessive Ideas." This article appeared in the journal Brain, between 1894 and 1895. The author discusses historical reasons that might explain Jackson's lack of influence on British psychiatry, in contrast to the considerable spread of his ideas on neurology.

Key words: Obsessive ideas, John Hughlings Jackson, Henry Ey, psychopathology history

(Henry Ey, Jackson et les idées obsédantes)

L'article souligne l'importante contribution du professeur de psychiatrie Henry Ey aux études de John Hughlings Jackson. Il analyse de façon historique une interface peu connue entre Jackson et la psychiatrie: le dialogue sur les "idées obsédantes" publié dans la revue Brain entre 1894 et 1895. Cet article discute d'ailleurs les raisons historiques qui pourraient expliquer le manque d'influence de Jackson sur la psychiatrie britannique qui contraste avec la large diffusion de ses positions en neurologie.

Mots clés: Idées obsédantes, John Hughlings Jackson, Henry Ey, psychopathologie histoire

(Henry Ey, Jackson y las ideas obsesivas)

El artículo destaca la importante contribución del profesor de psiquiatria Henry Ey a los estúdios sobre John Hughlings Jackson. Se analisa históricamente uma interfaz poço conocida de Jackson com la psiquiatria: el diálogo acerca de las "ideas obsesivas" que figura en las páginas de la revista Brain, entre 1894 y 1895. Se discute las razones históricas que pueden explicar la ausencia de influencia de Jackson em la psiquiatria britânica, lo que contrasta con la amplia difusión de sus posiciones en la neurologia.

Palabras clave: Ideas obsesivas, John Hughlings Jackson, Henry Ey, psicopatologia historia

Citação/Citation: Berrios, G.E. Henry Ey, Jackson e as ideias obsessivas. Revista Latinoamericana de Psicopatologia Fundamental, São Paulo, v. 14, n. 2, p. 367-382, jun.2011. 
Editor do artigo/Editor: Prof. Dr. Manoel Tosta Berlinck

Recebido/Received: 6.10.2010 / 10.6.2010 Aceito/Accepted: 15.1.2011 / 1.15.2011

Copyright: () 2009 Associação Universitária de Pesquisa em Psicopatologia Fundamental/ University Association for Research in Fundamental Psychopathology. Este é um artigo de livre acesso, que permite uso irrestrito, distribuição e reprodução em qualquer meio, desde que o autor e a fonte sejam citados/This is an open-access article, which permits unrestricted use, distribution, and reproduction in any medium, provided the original author and source are credited.

Financiamento/Funding: $\mathrm{O}$ autor declara não ter sido financiado ou apoiado/The author has no support or funding to report.

Conflito de interesses/Conflict of interest: $\mathrm{O}$ autor declara que não há conflito de interesses/The author declares that has no conflict of interest.

\section{German E. BerRIos}

Médico e filósofo pela Universidad Nacional de San Marcos, Lima, Peru; Psiquiatra; Neurologista; Psicólogo; Filósofo; Historiador e Filósofo da ciência (Oxford University, England); Professor de Neuropsiquiatria e de Epistemologia da Psiquiatria (University of Cambridge, England), desde 1976; Neuropsiquiatra e Chefe do Departamento de Neuropsiquiatria do Hospital Addenbrooke, University of Cambridge, por 32 anos; Coordenador do Comitê de Ética em Pesquisa com Humanos na mesma universidade, por 20 anos; Editor Responsável de History of Psychiatry; Autor de 14 livros, incluindo The History of Mental Symptoms, Descriptive Psychopathology since 19th Century (Prêmio Nacional BMA, 1997), A History of Clinical Psychiatry (com Roy Porter), e Delirio (com F. Fuentenebro) e mais de 400 artigos e capítulos de livros; Membro do Royal College of Psychiatrists; da Associação Britânica de Psicologia e da Academia Britânica de Ciências Médicas; Membro Vitalício do Robinson College, Cambridge; doutor Honoris-Causa da Universidade de Heidelberg (Alemanha), da Universidade Nacional Mayor de San Marcos (Peru) e da Universidad Autónoma de Barcelona (Espanha); Grão Oficial da Ordem del Sol (Condecoração do Governo Peruano, 2007); prêmio Ramon y Cajal 2008 concedido pela Asociación Internacional de Neuropsiquiatria.

University of Cambridge

Box 189, Hills Road

Cambridge,

UK CB2 2QQ

e-mail: geb11@cam.ac.uk 